\title{
Image, imaginaire, imaginer la maladie en 2011
}

\author{
F. Klotz \\ C) Springer-Verlag France 2011
}

Quel que soit le continent où il vit, le malade du XXI ${ }^{\mathrm{e}}$ siècle est confronté à une évolution rapide de son imaginaire stimulé par une part grandissante du monde virtuel, télétransporté, téléinfusé, téléobligé. Dans les contrées les plus reculées, l'imaginaire traditionnel est mis en compétition avec la réalité virtualisée et télétransmise absorbée passivement par le téléspectateur quels que soient son âge et sa culture. Les paraboles tournées vers les satellites fleurissent jusque sur les logis les plus pauvres de la planète.

L'imaginaire de l'être humain est construit comme une mosaïque sophistiquée faite de vécu, d'éducation, de culture, de frustrations de désirs, de plaisirs, de douleurs, de terreurs, de l'histoire et du quotidien de l'individu. L'adjonction d'une somme considérable d'images souvent violentes, plus rarement agréables, télétransmises passivement, métamorphose l'imaginaire du sujet d'autant qu'il n'a pas la culture pour avoir un esprit critique lui permettant de filtrer ces acquis passifs. La somme d'images et d'informations placées en décalcomanies dans l'inconscient participe de manière importante à l'imaginaire et le déforme dans sa fonction de contrepoids du réel.

Le rôle de l'imaginaire est essentiel dans la perception et l'acceptation de la maladie. Une grande part du volet mystique qui le composait a été remplacée par un catalogue d'images et de connaissances superficielles souvent crues, mais banalisées et aseptisées. L'individu est abreuvé par les émissions " grand public 》 et les séries télévisées utilisant invariablement l'amour, la violence, la maladie, la médecine, la mort. Le dialogue et la discussion avec les proches tendent à disparaître et ne servent plus de mise à distance de cet apport extérieur envahissant.

Si notre confrère Victor Segalen revenait, il serait surpris et peut-être inspiré par cette fuite de l'homme vers un monde virtuel, accélérée de manière exponentielle par la toile mon- diale tissée par Internet. Ce médecin, écrivain et poète passionné par l'Extrême-Orient, a recherché toute sa vie un monde imaginaire « au pays du réel ». Dans toute son œuvre parfois hermétique et difficile, l'être humain est l'objet que l'imaginaire et le réel se disputent. Il tend à démontrer que l'imaginaire ne peut s'entendre avec le réel, mais lui survit. «Dès maintenant, je puis tenir que le réel imaginé est terrible et le plus gros des épouvantails à faire peur » [1]. Entre l'imaginaire et le réel, c'est «l'instinct sauveteur » qui permet de survivre.

Le médecin de ce début du XxI ${ }^{\mathrm{e}}$ siècle doit composer avec l'imaginaire de son malade, en incluant dans le colloque singulier qu'il a avec lui non seulement les données traditionnelles et culturelles inhérentes à chaque région, mais aussi ces nouvelles données constitutives de l'inconscient. La somme d'informations " téléapportées 》 ne donnant pas du tout la même manière d'appréhender les sentiments que l'expérience vécue ou la culture acquise par un mode relationnel traditionnel. Cette absorption solitaire de l'image tend à niveler, à banaliser, à supprimer une dimension et à falsifier les émotions.

La pathologie digestive est riche d'imaginaire et se nourrit volontiers de celui-ci pour s'exprimer. Il faut que nous aidions nos patients à trouver une représentation acceptable de leur maladie en infléchissant leur imaginaire par une relation médecin-patient confiante, attentive, rassurante se servant éventuellement d'éléments " téléapportés » positifs pour conforter le lien et la confiance.

\section{Référence}

1. Segalen V (1929) «Équipée » (Voyage au pays du réel). Réédition 1999. Gallimard, Collection « L'imaginaire » 